\title{
New approach to the formation of organo-inorganic borosyloxane polymer structures
}

\author{
(C) Alexander B. Zachernyuk, ${ }^{1}$ Boris A. Zachernyuk, ${ }^{2}$ Ekaterina N. Solovyova, ${ }^{2}$ \\ Vladimir I. Nedelkin, ${ }^{3}$ Lyubov A. Korneeva, ${ }^{4}$ and Sergey G. Bezryadin ${ }^{5+}$ \\ ${ }^{1}$ Innovation Department. A.N.Nesmeyanov Institute of Organoelement Compounds \\ of RAS. Vavilova St., 28. Moscow, 119991.Russia.Phone: +7 (499) 135-93-84.E-mail: a_zacher@mail.ru \\ ${ }_{2}$ Chemistry and Ecotoxicology Division. Moscow State University of Food Production. Volokolamskoe \\ Shosse, 11. Moscow, 125080. Russia. Phone: +7 (499)750-01-11, add.7242.E-mail: zachern@rambler.ru \\ ${ }^{3}$ Road construction supplies Division. Moscow Automobile and Roud Construction State Technical \\ University (MADI). Leningradsky prospect 64. Moscow, 125319. Russia.E-mail:vinedelkin@mail.ru \\ ${ }^{4}$ Chemistry and Electric-Chemical Energetic Division. National Research University "MPEI". \\ Krasnokazarmennaya St., 14. Moscow, 111250. Russia. Phone: +7 (495) 362-70-31. \\ E-mail: korneevala@bk.ru \\ ${ }^{5}$ Chemical Technology of Oil Refining, Gas and Ecology Department, Gubkin Russian State University of Oil \\ and Gas (National Research University), Orenburg Branch. Yunykh Lenintsev St., 20. Orenburg, 460047. \\ Orenburg Region, Russia.Phone: +7 (3532)62-94-21.E-mail:sergbezryadin@mail.ru
}

Keywords: boron oxide, dichlorotetraphenyl disiloxane, borocyclosiloxanes, condensation, matrix, sol-gel methods.

*Supervising author; ${ }^{+}$Corresponding author

\section{Abstract}

Using sol-gel methods, new synthetic approaches to the preparation of boron-containing organicinorganic hybrid polymers based on boron oxide (boric anhydride), which is a part of many inorganic materials, have been developed. Previously, such methods were used to obtain amorphous silicate glasses and their use allows introducing various inorganic and organic modifiers into the matrix of silicon dioxide and other compounds at temperatures up to $120^{\circ} \mathrm{C}$.

Within the framework of this work: a) the conditions for obtaining saturated solutions of boron oxide in organic solvents were found and it was found that boric anhydride is most completely dissolved in triethyl orthoformiate (approximately $25 \%$ ) at $110-110{ }^{\circ} \mathrm{C}$ retaining its structure; $b$ ) by the condensation of boric acid with 1,3-dichlorotetraphenyl disiloxane, functional borcyclosiloxanes were synthesized to further modify boron oxide. The reaction conditions, spectral and thermal characteristics of condensation products were investigated. It is shown the increasing in the synthesis time to $15-18 \mathrm{~h}$, a bicyclic borsiloxane is formed; c) homophasic modification of boric anhydride with monofunctional cyclic borsiloxanes was carried out and it was shown that the formation of Si-O-B bonds at $110-120{ }^{\circ} \mathrm{C}$ occurs due to the use of anhydrous sol-gel process. Transparent films are obtained from modified boric anhydride solutions deposited on glass and stainless steel, followed by curing at a temperature of $160-280{ }^{\circ} \mathrm{C}$, that are not subjected to hydrolysis under the action of air moisture and are stable in air up to $600{ }^{\circ} \mathrm{C}$.

As a result of the work, the possibility of obtaining a borsiloxane type polymeric structures having an inorganic molecular skeleton modified with organosilicon compounds has been investigated.

\section{References}

[1] V.I. Nedel'kin, B.A. Zachernyuk, O.B. Andrianova, E.N. Solov'yeva, A.B. Zachernyuk, and N.S. Chernova. Oligo(phenylene sulfide)s containing terminal thiol groups. Butlerov Communications. 2013. Vol.35. No.7. P.163-166. ROI: jbc-02/13-35-7-163

[2] A.B. Zachernyuk, A.M. Muzafarov. Abstr. of the XVII All-Russian Conference "Structure and Dynamics of Molecular Systems", Yalchik, June 26-July 3. 2010. P.78. (russian)

[3] G.C. Righini, M.A. Forastiere, M. Guglielmi, A. Martucd, in: SPIEProc. 3280. Rare-Earth-Doped Devices II, paper 10, 1998.

[4] D.A. Foucher, A.J. Lough, J. Manner. Inorg.Chem. 1992. Vol.31. P.3034-3043.

[5] C. Zha, G.R. Atkins, A.F. Masters. Ninth International Workshop in Glasses, Ceramics, Hybrids and Nanocomposites from Gels, Sheffild, UK. 31 August-5 September 1997. P.955. 